\title{
A fully automated linear polyacrylamide coating and regeneration method for capillary electrophoresis of proteins
}

\author{
J. Bodnar ${ }^{1}$, L. Hajba ${ }^{1}$ and A. Guttman ${ }^{1,2 *}$ \\ ${ }^{1}$ MTA-PE Translational Glycomics Research Group, University of Pannonia, Veszprem, \\ Hungary \\ ${ }^{2}$ Horváth Csaba Memorial Institute for Bioanalytical Research, University of Debrecen, \\ Debrecen, Hungary
}

*Author to whom correspondence should be addressed. Email: guttman@mik.uni-pannon.hu

Keywords: capillary coating, linear polyacrylamide, automation

Abbreviations: LPA - linear polyacrylamide, TEMED - N,N,N',N'-tetramethylethylendiamine, APS - ammonium persulfate, BGE - background electrolyte, CE - capillary electrophoresis, BFS - bare fused silica, RSD - relative standard deviation

\begin{abstract}
Surface modification of the inner capillary wall in CE of proteins is frequently required to alter electroosmotic flow and to prevent protein adsorption. Manual protocols for such coating techniques are cumbersome. In this paper an automated covalent linear polyacrylamide coating and regeneration process is described to support long term stability of fused silica capillaries for protein analysis. The stability of the resulting capillary coatings was evaluated by a large number of separations using a three-protein test mixture in $\mathrm{pH} 6$ and $\mathrm{pH} 3$ buffer systems. The results were compared to that obtained with the use of bare fused silica capillaries. If necessary, the fully automated capillary coating process was easily applied to regenerate the capillary to extend its useful life-time.
\end{abstract}

Received: MONTH DD, YYY; Revised: MONTH DD, YYY; Accepted: MONTH DD, YYY

This article has been accepted for publication and undergone full peer review but has not been through the copyediting, typesetting, pagination and proofreading process, which may lead to differences between this version and the Version of Record. Please cite this article as doi: 10.1002/elps.201600405.

This article is protected by copyright. All rights reserved. 


\section{Introduction}

Capillary electrophoresis (CE) is a very important separation technique for the analysis of proteins [1]. Charged protein molecules are separated in $\mathrm{CE}$ by their differential electrophoretic mobilities at the appropriate $\mathrm{pH}$, which should be defined based on their isoelectric points. However, when the background electrolyte $\mathrm{pH}>3$, the surface of the most frequently used capillary tubing material of bare fused silica (BFS) becomes increasingly negatively charged, inducing the formation of an electric double layer. This consequently results in a common electrokinetic phenomenon, i.e., by the application of an electric field, this layer induces a bulk electroosmotic flow (EOF). In addition, the negatively charged silica surface can adsorb protein molecules. Therefore, modification of the inner surface of the separation capillary is very important in $\mathrm{CE}$ of proteins to avoid analyte adsorption and to alter the electroosmotic flow.

Capillary wall coatings can be classified as dynamic or permanent types, based on the mode of the attachment of the coating material [2]. Dynamic capillary coatings offer simple and cost-effective ways to alter EOF. The most frequently used methods are based on reversible adsorption of small ions, like amines or oligo-amines, anionic and cationic surfactants (sodium dodecyl sulfate - SDS, cetyltrimethylammonium bromide - CTAB, etc.) or neutral hydrophilic polymers, such as polyethylene oxide (PEO), poly-vinyl alcohol (PVA), celluloses and dextrans [3, 4]. These coating agents are simply added to the background electrolyte (BGE), which makes them easy to apply [3-6]. However, in some cases dynamic coating agents may interfere with the separation and/or detection systems. An example for the latter one is mass spectrometry (MS), where the coating material entering the mass spectrometer may cause problems like high background noise, suppression of analyte signals, and/or contamination of the ion source and ion optics [7]. The use of permanent surface coatings alleviates most of these issues.

Permanent coatings are irreversibly attached to the inner surface of the silica capillary wall and therefore not part of the BGE. The two most important types of permanent coatings are physical coatings and covalent (chemical) coatings $[8,9]$. The advantages of physical coatings compared to covalent coatings are: (i) the simplicity of the coating process; (ii) ease of coating regeneration; and (iii) limited dependence on surface chemistry [10, 11]. Permanent physical coating occurs through the formation of hydrogen bonds, electrostatic, hydrophobic or other stable physical interactions with the silica surface [12]. Automation of surface coating procedures were attempted earlier using a homemade device for physically adsorbed coatings [13].

Covalent (chemical) capillary coatings on the other hand represent the most prevalent and effective strategy to prevent biomolecular adsorption and to alter electroosmotic flow in CE [10]. Preparation of covalent coatings typically comprises the following three steps: 1) pre-treatment of the fused silica surface to open up the Si-O-Si bonds, 2) reacting the open

This article is protected by copyright. All rights reserved. 
silanol groups with a bifunctional reagent, and 3) binding the coating material (e.g., linear polymer) through the bifunctional reagent [2]. Some of the great advantages of covalent coatings are their long-term stability and compatibility with MS detection [7]. Delaunay and coworkers reported on a linear polyacrylamide coating process, where the rinsing steps were implemented in a $\mathrm{CE}$ instrument and the drying process were performed in a gas chromatography oven [14]. To increase the lifetime of covalent surface coverage, double coating procedures utilizing a hydrophobic primary layer and a hydrophilic upper layer was also reported in the literature [15].

In this paper we describe a fully automated covalent linear polyacrylamide coating and regeneration method for capillary electrophoresis of proteins, adapted from the original Hjertén method [16] and implemented in a commercial CE instrument. In our approach, the capillary stays in the $\mathrm{CE}$ instrument during the entire coating or regeneration process. A comparison between the separation performance of a three protein test mixture using uncoated as well as manually and automatically coated / regenerated capillaries is also discussed.

\section{Experimental}

\section{Chemicals and reagents}

Methanol, sodium hydroxide and acrylamide were purchased from VWR (Radnor, PA, USA). Ammonium persulfate (APS) was from AMRESCO (Solon OH, USA) and N,N,N',N'- tetramethyl-ethylendiamine (TEMED) was from Alfa Aesar (Karlsruhe, Germany). The 3-(trimethoxysilyl)propyl methacrylate and all other chemicals were purchased from Sigma Aldrich (St. Louis, MO, USA). The Protein Methods Development kit containing the $\mathrm{pH} 3$ Citrate Buffer $(50 \mathrm{mM})$, pH 6 Citrate/MES buffer $(50 \mathrm{mM})$, as well as the Protein Test Mixture of lysozyme, ribonuclease $\mathrm{A}$ and cytochrome $\mathrm{C}$ was from SCIEX (Brea, CA, USA). The $75 \mu \mathrm{m}$ ID / $375 \mu \mathrm{m}$ OD bare fused silica capillary tubing was from Polymicro Technologies (Phoenix, AZ, USA)

\section{Instrumentation}

A PA 800 Plus Pharmaceutical Analysis System equipped with a variable wavelength UV/VIS detector was used for the capillary coating and regeneration processes as well as the CE separations (SCIEX). Separations were accomplished in $20 \mathrm{~cm}$ effective length $(30 \mathrm{~cm}$ total length) linear polyacrylamide (LPA) coated, regenerated and bare fused silica capillary columns, filled either with $\mathrm{pH} 3$ citrate or $\mathrm{pH} 6$ citrate/MES buffer without any acidic, alkaline or organic pre- or between-run-treatments. The applied electric field strength was $500 \mathrm{~V} / \mathrm{cm}$ with normal polarity mode (cathode at the detection side). The separation temperature was set to $25^{\circ} \mathrm{C}$ and the detection wavelength was $214 \mathrm{~nm}$. The Protein Test

This article is protected by copyright. All rights reserved. 
Mixture was injected by 0.5 psi pressure for $3 \mathrm{~s}$. Data acquisition and processing was performed by the 32 Karat version 9.0 software package (SCIEX).

\section{Manual coating process}

First, the Si-O-Si groups of the fused silica capillary inner surface were opened by a slow 1 $\mathrm{M} \mathrm{NaOH}$ rinse (100 $\mu$ l volume) using a Hamilton syringe with a Teflon connection to the capillary. Then the capillary was washed with $100 \mu \mathrm{l}$ of water followed by rinsing with 100 $\mu \mathrm{l}$ of methanol. The resulting Si-OH groups were then reacted with freshly prepared $4 \%$ aqueous 3-(trimethoxysilyl)propyl methacrylate by slow intermittent rinsing for $1 \mathrm{~h}$ using a Hamilton syringe (100 $\mu \mathrm{l}$ volume). Next, the capillary was filled with a freshly prepared aqueous polymerization mixture of $4 \%$ acrylamide monomer containing $0.05 \%$ TEMED (catalyst) and $0.05 \%$ APS (initiator) with the ends of the tubing immersed into reaction mixture filled microfuge tubes. The capillary was kept for $1 \mathrm{~h}$ in dark to proceed with the polymerization reaction. The reaction mixture was then removed from the capillary by water rinse using a Hamilton syringe and the coated capillary was then filled with the respective background electrolytes for evaluation.

\section{Fully automated coating and regeneration process}

The PA 800 Plus capillary electrophoresis instrument was used to implement the fully automated coating and regeneration procedure. The basic principles of this process were the same as described above in the manual coating protocol section.

- Step 1: the bare fused silica capillary was rinsed with $1 \mathrm{M} \mathrm{NaOH}$ by applying 60 psi pressure (Scheme 1, Panel a) for $5 \mathrm{~min}$ followed by water and methanol rinse at 20 psi for 2 min, respectively.

- Step 2: The generated silanol groups were then reacted with freshly prepared 4\% 3(trimethoxysilyl)propyl methacrylate reagent by applying 2 psi pressure rinse for $1 \mathrm{~h}$ (Scheme 1, Panel b).

- Step 3: Then the capillary was filled with the aqueous reaction mixture of $0.05 \%$ TEMED containing $4 \%$ acrylamide monomer solution by applying 50 psi pressure for $2 \mathrm{~min}$ in reversed rinse mode (from the detection side, Scheme 1, Panel c).

- Step 4: The ammonium persulfate initiator was introduced under optimized conditions (15 $\mathrm{kV}$ in reversed polarity mode for $2 \mathrm{~min}$ ) from a 10\% APS filled cathodic reservoir (Scheme 1 , Panel d). During this step, the $0.05 \%$ TEMED containing $4 \%$ acrylamide monomer solution was in the anodic reservoir.

This article is protected by copyright. All rights reserved. 
The use of reversed polarity mode (cathode at the injection side) caused migration of the negatively-charged persulfate ions towards the detection end of the capillary, with opposite electromigration of the positively-charged TEMED molecules towards the injection end of the tube as depicted in Scheme 1, Panel d. This allowed intensive mixing of the uncharged acrylamide monomer with the negatively-charged initiator and positively-charged catalyst molecules resulting in efficient in situ polymerization reaction within the capillary. The light needed to start the free radical polymerization process was provided by applying the entire wavelength range of the UV/VIS detector (no filter) transmitted through the capillary detection window (Scheme 1, Panel d). The reaction mixture remained in the capillary for one hour followed by high pressure rinse ( $80 \mathrm{psi}$ ) with the appropriate separation buffer for $5 \mathrm{~min}$.

The stability of resulted coating was tested by running the Protein Test Mixture in multiple times using the same buffer to rinse the column between the separations. When signs of coating deterioration were apparent (migration time shift, peak broadening, etc.), regeneration of the capillary coating was accomplished by applying Step 2 - Step 4 of the above described automated procedure.

\section{Results and discussion}

The general aim of our work was to develop a simple, rapid, cost-effective and automated method for coating (and regeneration of coating) of fused silica capillary tubings with linear polyacrylamide (LPA) to decrease electroosmotic flow and reduce possible adsorption of proteins or any other solute molecules. The fully automated process took advantage of the opposite electromigration properties of the negatively-charged ammonium persulfate initiator and the positively-charged TEMED catalyst (Scheme 1, Panel d) with the uncharged acrylamide monomer filled capillary tubing. Prior to the polymerization reaction, the 3-(trimethoxysilyl)propyl methacrylate bifunctional reagent was covalently attached to the activated (NaOH treated) inner silica capillary wall via its silane functional group (Scheme 1, Panel c), while the free methacrylate group took part in the acrylamide polymerization process (Scheme 1, Panel d).

Figure 1 compares a large number of separations of the Protein Test Mixture (lysozyme, cytochrome $\mathrm{C}$ and ribonuclease A) on a bare fused silica (BFS) capillary (1A), as well as after manual linear polyacrylamide (LPA) coating (1B), automated LPA coating (1C) and automated LPA coating regeneration (1D), using the $\mathrm{pH} 6$ citrate/MES buffer system. Figure 1A reveals continuously increasing migration times from 5.41 to $7.14 \mathrm{~min}, 6.23$ to $8.67 \mathrm{~min}$ and 8.39 to $13.61 \mathrm{~min}$ for the test mixture components of lysozyme ( $\mathrm{pI}=11.35)$, cytochrome $\mathrm{C}(\mathrm{pI}=10.0-10.5)$ and ribonuclease $\mathrm{A}(\mathrm{pI}=9.3)$, respectively, over the course of only 12 runs, probably due to the combined effects of surface adsorption and increasingly developing electroosmotic flow. The separation performance was tested with buffer rinse only inbetween runs. Table 1 depicts the migration times and the run-to-run their relative standard

This article is protected by copyright. All rights reserved. 
deviations for the test mixture components of lysozyme ( $\mathrm{RSD}=8.51 \%$ ), cytochrome $\mathrm{C}$ $(\mathrm{RSD}=10.03 \%)$ and ribonuclease $\mathrm{A}(\mathrm{RSD}=14.43 \%)$ using the BFS capillary.

Figure $1 \mathrm{~B}$ shows the separation of the Protein Text Mixture in the same $\mathrm{pH} 6$ citrate/MES buffer system in a manually LPA coated capillary. One can observe the excellent migration time stability that was maintained at least up to a hundred runs. As Table 1 shows, here the relative standard deviations were only $0.36 \%, 0.44 \%$ and $0.63 \%$ for the test mixture components. The efficiency of the automated coating procedure was similar to the manual process as demonstrated by the separation traces in Figure 1C. The automated coating process resulted in even lower migration time variance of $0.31 \%, 0.31 \%$ and $0.33 \%$ RSD after the first coating and $0.14 \%, 0.2 \%$ and $0.55 \%$ RSD after coating regeneration for lysozyme, cytochrome $\mathrm{C}$ and ribonuclease A, respectively. These results strongly suggested that the automated coating and regeneration process could be readily applied to lengthen the lifetime of the linear polyacrylamide coated capillary column for up to hundreds of separations.

The above described stability tests for the linear polyacrylamide coated and regenerated capillaries were also repeated with the use of $\mathrm{pH} 3$ Citrate buffer. Figure 2 compares the Protein Test Mixture separation results on an uncoated bare fused silica capillary (2A) with the manually coated (2B), as well as using the automated coating (2C) and regeneration (2D) processes. Albeit, at this $\mathrm{pH}$ no significant EOF generation was expected, differences were still observed in the migration time variances of the model test proteins between the coated capillaries and their uncoated counterparts (Figure 2A vs 2B-D). The average migration time RSD values were $1.1 \%, 0.6 \%$ and $0.7 \%$ for the manually, automatically, and automatically regenerated capillaries, respectively, while for the bare fused silica capillary it was $3.2 \%$. Similar to the results with the $\mathrm{pH} 6$ buffer system, automated coating and regeneration significantly lengthened the lifetime of the linear polyacrylamide coated capillary.

\section{Conclusions}

A fully automated covalent capillary coating and regeneration method is described to alleviate the labor intensive manual process. The stability of the linear polyacrylamide coating was evaluated by using a three-protein containing test mixture of lysozyme, cytochrome $\mathrm{C}$ and ribonuclease A with $\mathrm{pH} 6$ and $\mathrm{pH} 3$ buffer systems. The inner surface of the fused silica capillaries were coated by linear polyacrylamide in an automated fashion by electrokinetically driving the positively-charged catalyst and the negatively-charged initiator reagents into the uncharged acrylamide monomer filled capillary tubing, taking advantage of their opposite charge states and concomitant electromigration properties. The resulted capillary coating was very stable up to at least of a hundred runs. An automated regeneration process was also applied to provide an option to extend the useable lifetime of the linear polyacrylamide coated capillary column up to several hundred runs.

This article is protected by copyright. All rights reserved. 


\section{Acknowledgements}

This paper is dedicated to the memory of our colleague and good friend Dr Craig Lunte. The authors gratefully acknowledge the support of the Momentum (Lendulet) grant \# 97101 of the Hungarian Academy of Sciences (MTA-PE Translational Glycomics Group) and the NKFIH (K 116263) grant of the Hungarian Government. The authors have no conflict of interest.

\section{Figures and Tables}

This article is protected by copyright. All rights reserved. 

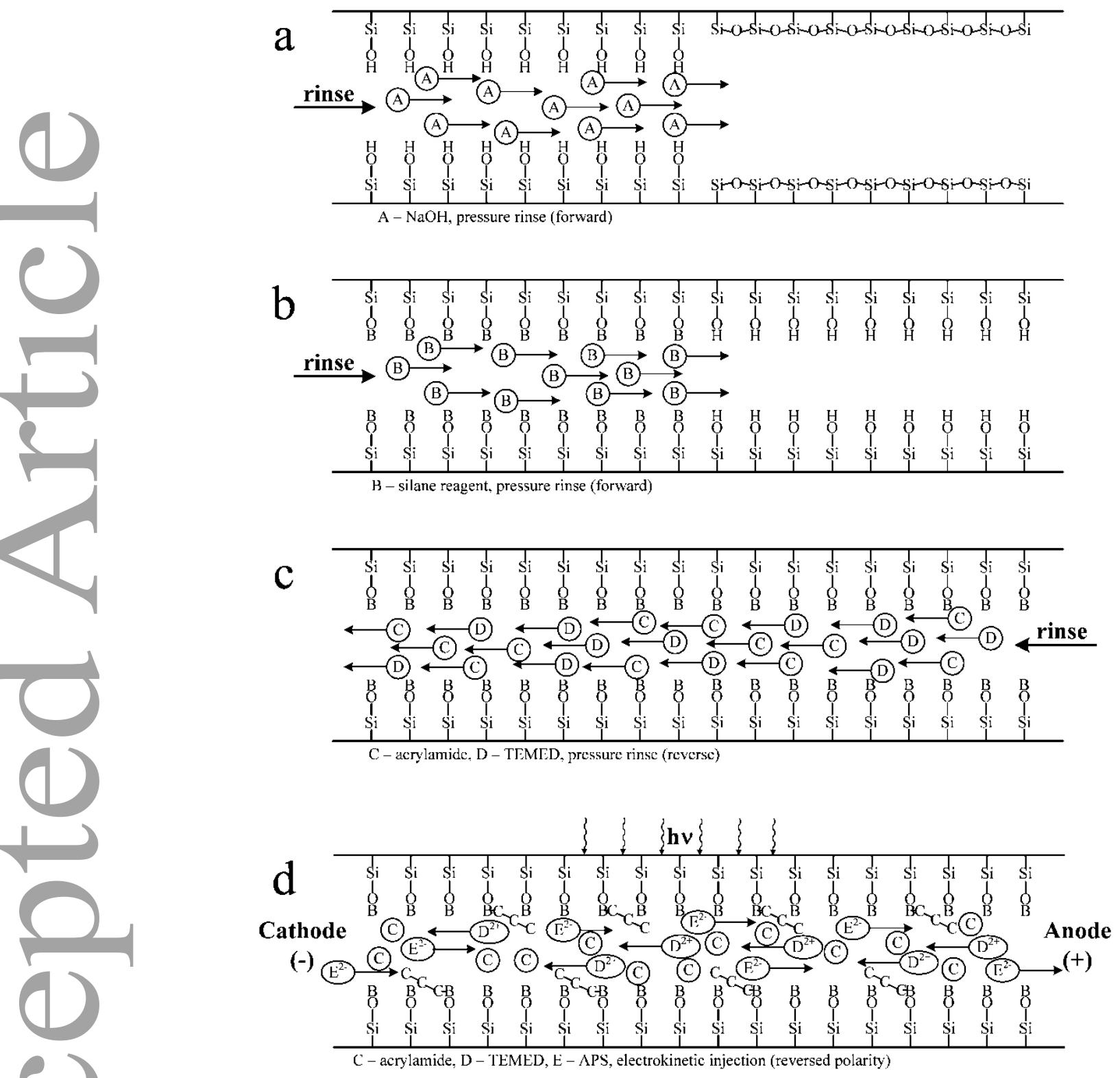

Scheme 1. Schematic representation of the automated capillary coating and regeneration process taking advantage of the opposite electromigration of the positively-charged catalyst (TEMED) and negatively-charged initiator (APS) reagents into the uncharged acrylamide monomer filled capillary tubing. a) rinse with $1 \mathrm{M} \mathrm{NaOH}$ solution; b) rinse with freshly prepared aqueous solution of 4\% 3-(trimethoxysilyl)propyl methacrylate; c) filling the capillary with $4 \%$ acrylamide monomer, containing $0.05 \%$ TEMED; d) applying the electric field in reversed polarity mode to force the electromigration of the negatively-charged persulfate ions towards the detection end and the positively charged TEMED molecules towards the injection end. UV irradiation through the detection window was used to start the free-radical polymerization reaction.

This article is protected by copyright. All rights reserved. 

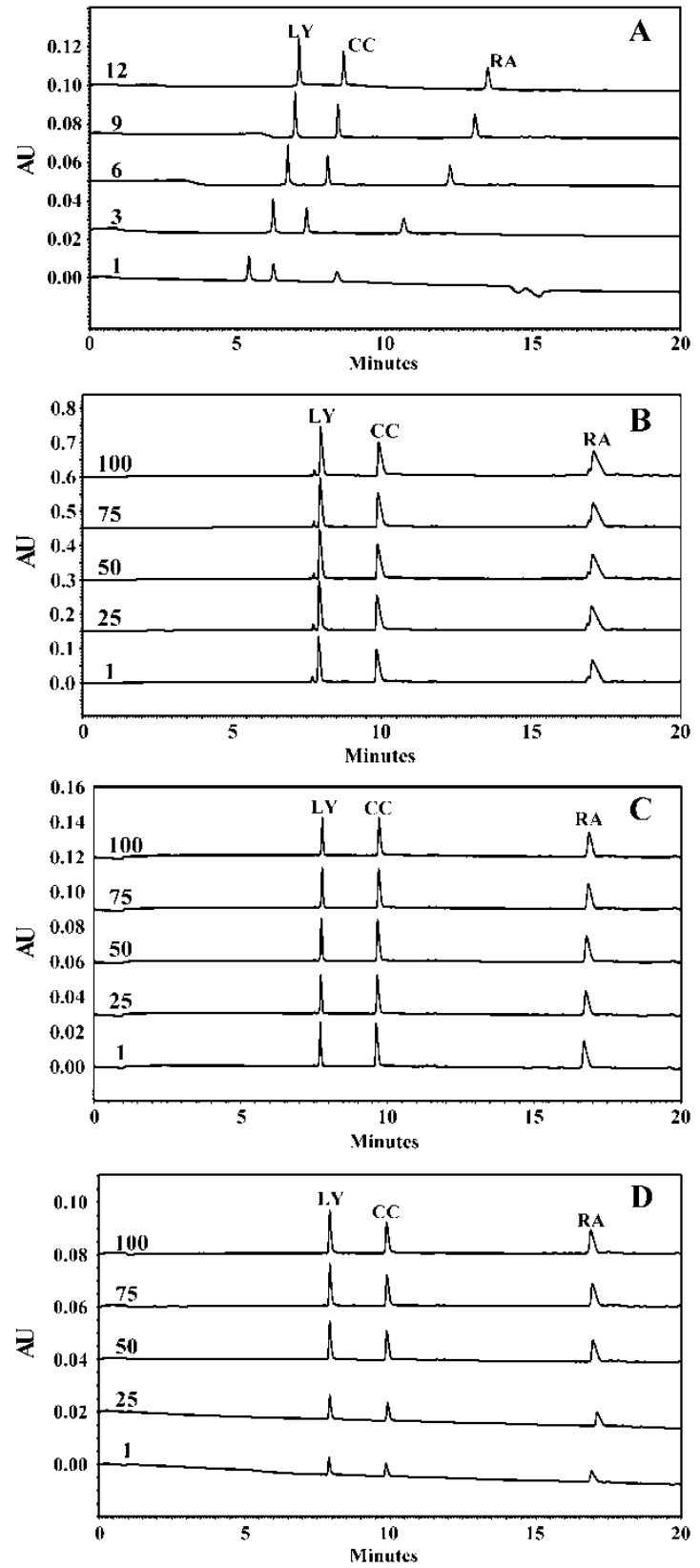

Figure 1. Comparison of multiple separations of the Protein Test Mixture on a bare fused silica capillary (A), as well as after manual linear polyacrylamide (LPA) coating (B), automated LPA coating (C) and automated coating regeneration (D) using the $\mathrm{pH} 6$ citrate/MES buffer system. LY: lysozyme, CC: cytochrome C and RA: ribonuclease A. Numbers above the traces represent the actual run numbers. Conditions: capillary length: 20 $\mathrm{cm}$ (effective, $30 \mathrm{~cm}$ total); detection: UV $214 \mathrm{~nm}$; E=500 V/cm normal polarity; separation temperature: $25^{\circ} \mathrm{C}$; injection: $0.5 \mathrm{psi} / 3 \mathrm{sec}$.

This article is protected by copyright. All rights reserved. 

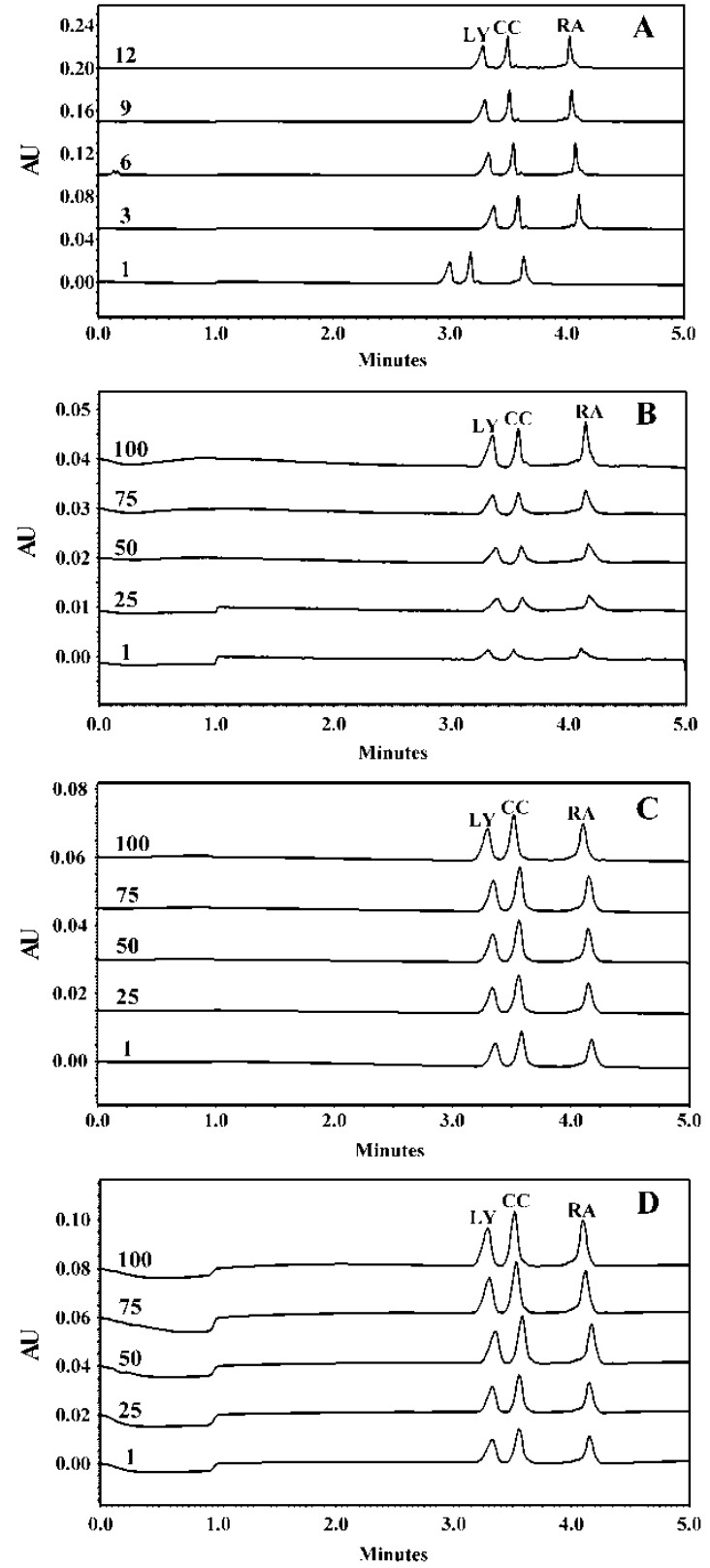

Figure 2. Comparison of multiple separations of the Protein Test Mixture on a bare fused silica capillary (A), as well as after manual LPA coating (B), automated LPA coating (C) and automated coating regeneration (D) using the $\mathrm{pH} 3$ citrate buffer system. Peaks and conditions were the same as in Figure 1.

Table 1. Migration times and their run-to-run relative standard deviations (\%RSD) of the lysozyme, cytochrome $\mathrm{C}$ and ribonuclease $\mathrm{A}$ test mixture components using the uncoated

This article is protected by copyright. All rights reserved. 
bare fused silica, the manually linear polyacrylamide (LPA) coated as well as the automatically LPA coated and regenerated capillaries.

\begin{tabular}{|c|c|c|c|c|c|c|c|c|}
\hline \multirow{2}{*}{$\begin{array}{l}\text { Capillary } \\
\text { Type }\end{array}$} & \multicolumn{4}{|c|}{$\begin{array}{c}\text { Migration times in pH citrate/MES } 6 \\
\text { buffer (min) }\end{array}$} & \multicolumn{4}{|c|}{$\begin{array}{c}\text { Migration times in pH } 3 \text { citrate } \\
\text { buffer (min) }\end{array}$} \\
\hline & & $\begin{array}{c}\text { Lysozy } \\
\text { me }\end{array}$ & $\begin{array}{l}\text { Cytochrom } \\
\text { e C }\end{array}$ & $\begin{array}{c}\text { RNase } \\
\text { A }\end{array}$ & & $\begin{array}{l}\text { Lysozy } \\
\text { me }\end{array}$ & $\begin{array}{l}\text { Cytochrom } \\
\text { e C }\end{array}$ & $\begin{array}{l}\text { RNa } \\
\text { se A }\end{array}$ \\
\hline $\begin{array}{c}\text { Bare } \\
\text { fused } \\
\text { silica } \\
\text { capillary }\end{array}$ & $\begin{array}{c}\text { Avera } \\
\text { ge } \\
\text { RSD } \\
\%\end{array}$ & 6.584 & 7.880 & 11.859 & $\begin{array}{c}\text { Avera } \\
\text { ge } \\
\text { RSD } \\
\%\end{array}$ & 3.280 & 3.485 & $\begin{array}{c}4.00 \\
3 \\
3.19\end{array}$ \\
\hline $\begin{array}{l}\text { Manually } \\
\text { LPA } \\
\text { coated } \\
\text { capillary }\end{array}$ & $\begin{array}{c}\text { Avera } \\
\text { ge } \\
\text { RSD } \\
\%\end{array}$ & 7.941 & 9.883 & 17.096 & $\begin{array}{c}\text { Avera } \\
\text { ge } \\
\text { RSD } \\
\%\end{array}$ & 3.357 & 3.572 & $\begin{array}{c}4.14 \\
5 \\
\\
1.09\end{array}$ \\
\hline $\begin{array}{c}\text { Fully } \\
\text { automate } \\
\text { d LPA } \\
\text { coated } \\
\text { capillary }\end{array}$ & $\begin{array}{l}\text { Avera } \\
\text { ge } \\
\text { RSD } \\
\%\end{array}$ & 7.758 & 9.679 & 16.799 & $\begin{array}{c}\text { Avera } \\
\text { ge } \\
\text { RSD } \\
\%\end{array}$ & 3.331 & 3.552 & $\begin{array}{c}4.13 \\
8\end{array}$ \\
\hline $\begin{array}{c}\text { Fully } \\
\text { automate } \\
\text { d LPA } \\
\text { coating } \\
\text { regenerat } \\
\text { ion }\end{array}$ & $\begin{array}{l}\text { Avera } \\
\text { ge } \\
\text { RSD } \\
\%\end{array}$ & 7.932 & 9.894 & 16.988 & $\begin{array}{l}\text { Avera } \\
\text { ge } \\
\text { RSD } \\
\%\end{array}$ & 3.321 & 3.549 & $\begin{array}{c}4.13 \\
9\end{array}$ \\
\hline
\end{tabular}

\section{References}

[1] Wehr, T., Rodriguez-Diaz, R., Zhu, M., Capillary electrophoresis of Proteins, Marcel Dekker (CRC Press), New York 1998.

[2] Horvath, J., Dolnik, V., Electrophoresis 2001, 22, 644-655.

[3] Melanson, J. E., Baryla, N. E., Lucy, C. A., Trac-Trend Anal Chem 2001, 20, 365-374.

[4] Righetti, P. G., Gelfi, C., Verzola, B., Castelletti, L., Electrophoresis 2001, 22, 603-611.

This article is protected by copyright. All rights reserved. 
[5] Chang, W. W. P., Hobson, C., Bomberger, D. C., Schneider, L. V., Electrophoresis 2005, 26, 2179-2186.

[6] Muijselaar, W. G. H. M., Debruijn, C. H. M. M., Everaerts, F. M., J Chromatogr 1992, 605, 115-123.

[7] Huhn, C., Ramautar, R., Wuhrer, M., Somsen, G. W., Anal Bioanal Chem 2010, 396, 297-314.

[8] Liu, C. Y., Electrophoresis 2001, 22, 612-628.

[9] Rodriguez, I., Li, S. F. Y., Anal Chim Acta 1999, 383, 1-26.

[10] Doherty, E. A. S., Meagher, R. J., Albarghouthi, M. N., Barron, A. E., Electrophoresis 2003, 24, 34-54.

[11] Lucy, C. A., MacDonald, A. M., Gulcev, M. D., J Chromatogr A 2008, 1184, 81-105.

[12] Robb, C. S., J Liq Chromatogr R T 2007, 30, 729-759.

[13] Chiari, M., Cretich, M., Damin, F., Ceriotti, L., Consonni, R., Electrophoresis 2000, 21, 909-916.

[14] Beneito-Cambra, M., Anres, P., Vial, J., Gareil, P., Delaunay, N., Talanta 2016, 150, 546-552.

[15] Shieh, P. C. H., Hoang, D., Guttman, A., Cooke, N., J Chromatogr A 1994, 676, $219-$ 226.

[16] Hjerten, S., J Chromatogr 1985, 347, 191-198.

This article is protected by copyright. All rights reserved. 